\title{
Fear not! Anxiety biases attentional enhancement of threat without impairing working memory filtering
}

\author{
Christine Salahub $^{1}$ (D) Stephen M. Emrich ${ }^{1}$
}

Accepted: 5 September 2020 / Published online: 18 September 2020

(C) The Psychonomic Society, Inc. 2020

\begin{abstract}
Individuals with anxiety have attentional biases toward threat-related distractors. This deficit in attentional control has been shown to impact visual working memory (VWM) filtering efficiency, as anxious individuals inappropriately store threatening distractors in VWM. It remains unclear, however, whether this mis-allocation of memory resources is due to inappropriate attentional enhancement of threatening distractors, or to a failure in suppression. Here, we used a systematically lateralized VWM task with fearful and neutral faces to examine event-related potentials related to attentional selection (N2pc), suppression $\left(\mathrm{P}_{\mathrm{D}}\right)$, and working memory maintenance (CDA). We found that state anxiety correlated with attentional enhancement of threatrelated distractors, such that more anxious individuals had larger N2pc amplitudes toward fearful distractors than neutral distractors. However, there was no correlation between anxiety and memory storage of fearful distractors (CDA). These findings demonstrate that anxiety biases attention toward fearful distractors, but that this bias does not always guarantee increased memory storage of threat-related distractors.
\end{abstract}

Keywords Attention · Working memory $\cdot$ Cognitive control $\cdot$ ERP $\cdot$ Anxiety

\section{Introduction}

Humans are wired to attend to and identify threat, such as a potentially dangerous snake in the grass (Öhman et al., 2001; Öhman \& Mineka, 2001). Even when these threatening stimuli are task-irrelevant, they manage to capture attention, suggesting that threat detection is a relatively automatic process (Beck \& Clark, 1997; Hodsoll et al., 2011; Mogg \& Bradley, 1999; but see, Pessoa, 2005). Although it is important to notice these dangers, threat-detection can become disadvantageous if taskirrelevant information cannot be ignored in favor of taskrelevant information. This is especially true for individuals with anxiety disorders, who are more likely to attend to threatening stimuli, delay disengagement from those stimuli, and to

Electronic supplementary material The online version of this article (https://doi.org/10.3758/s13415-020-00831-3) contains supplementary material, which is available to authorized users.

Christine Salahub

christine.salahub@brocku.ca

1 Department of Psychology, Brock University, 1812 Sir Isaac Brock Way, St. Catharines, Ontario L2S 3A1, Canada interpret ambiguous information as threatening (Bishop, 2007; Fox et al., 2001; Mathews \& Mackintosh, 1998). Even for individuals with subclinical levels of anxiety, there is a threat-related attentional bias toward irrelevant information (Bar-Haim et al., 2007; Stout et al., 2013), implicating general prefrontal attentional control deficits across a range of anxiety levels, and not just for individuals who are clinically diagnosed (Bishop, 2009; Bishop, Duncan, Brett, \& Lawrence, 2004a).

Although it is widely known that anxiety is related to deficits in attentional control abilities, this deficit does not always impact behavioral performance. Instead, anxiety is thought to affect neural processing efficiency (i.e., how cognitive resources are used to achieve a goal), whether that be through greater attentional capture or delayed suppression of threatening distractors (Eysenck et al., 2007; Gaspar \& McDonald, 2018). It has been proposed that individuals with anxiety can compensate for inefficient processing by investing more cognitive effort into the task, allowing them to maintain performance at the same level as less anxious individuals (Berggren \& Derakshan, 2013; Derakshan \& Eysenck, 2009; Eysenck et al., 2007; Gaspar \& McDonald, 2018).

Because processing efficiency cannot be inferred from behavioral performance alone, event-related potentials (ERPs) have been used to examine attentional selection and 
suppression of distracting emotional information. One ERP component that has been used to assess attentional enhancement and selection of stimuli is the N2 posterior contralateral (N2pc), which occurs 200-300 ms after the onset of a search display (Eimer, 1996; Hickey et al., 2006; Luck \& Hillyard, 1994a). The N2pc is affected by stimulus emotionality, with larger and earlier N2pcs toward threat-related than neutral or happy stimuli, regardless of their task relevance (Burra et al., 2016; Eimer \& Kiss, 2007; Feldmann-Wüstefeld et al., 2011; Holmes et al., 2009; Kappenman et al., 2015). Attentional enhancement of threatening stimuli is magnified for individuals who have high levels of anxiety (Fox et al., 2008). This bias extends to neutral distractors, as there is evidence that non-emotional distractors also elicit an N2pc in anxious individuals (Gaspar \& McDonald, 2018; Moran \& Moser, 2015; but see, Qi, Ding, \& Li, 2014).

Beyond attentional enhancement of distractors, it has also been found that active attentional suppression of threatening information is impaired in anxious individuals (Ansari \& Derakshan, 2011). An ERP component called the distractor positivity, or $\mathrm{P}_{\mathrm{D}}$, has been used to measure active inhibition/ suppression of salient distractors (Burra \& Kerzel, 2014; Gaspelin \& Luck, 2018; Hickey et al., 2009; Sawaki et al., 2012). There are two main time windows where the $P_{D}$ is typically found: early (140-190 ms) and later (200-400 ms). The early $\mathrm{P}_{\mathrm{D}}$ (also referred to as the $\mathrm{Ppc}$ ) is thought to reflect pre-attentive sensory imbalances in item salience, or suppression of the "attend-to-me" signal (Fortier-Gauthier et al., 2012; Gaspelin \& Luck, 2018; Sawaki \& Luck, 2010; Weaver et al., 2017), whereas the later $\mathrm{P}_{\mathrm{D}}$ occurs during or after the time range of the $\mathrm{N} 2 \mathrm{pc}$, and indicates an active suppression process, regardless of initial attentional capture (Gaspar \& McDonald, 2014; Sawaki \& Luck, 2013; for a review, see Jannati et al., 2013).

Active suppression is more difficult when the distractor is threatening, such that $\mathrm{P}_{\mathrm{D}}$ amplitudes are larger for angry face distractors than for happy distractors (Burra et al., 2017). Additionally, the timing of distractor suppression is delayed by threatening stimuli such as spiders (Burra et al., 2019). To our knowledge, no study has examined the correlation between anxiety and $\mathrm{P}_{\mathrm{D}}$ amplitude toward threat-related distractors. However, there is evidence that individuals with high anxiety are capable of suppressing non-emotional distractors, as individuals with anxiety exhibit a late $\mathrm{P}_{\mathrm{D}}$ following initial attentional capture (Gaspar \& McDonald, 2018). This finding suggests that attentional enhancement (N2pc) may be more critically affected by anxiety than distractor suppression $\left(\mathrm{P}_{\mathrm{D}}\right)$.

Deficits in attentional control for anxious individuals extend to visual working memory (VWM) storage. In particular, individuals with anxiety fail to filter irrelevant, threat-related faces from VWM (for a review see, Gambarota \& Sessa, 2019). Impaired filtering can be measured by an ERP that is associated with the amount of information maintained in
VWM: the contralateral delay activity (CDA; Ikkai et al., 2010; McCollough et al., 2007; Vogel et al., 2005). Stout et al. (2013) found that dispositional anxiety correlated with CDA amplitude when fearful face distractors were present in the memory array, such that the more anxious the individual, the more likely that a threatening distractor would be erroneously stored in memory (also seen with salient neutral distractors; Qi et al., 2014). Further, using fMRI, Stout et al. (2017) found that this anxiety-driven mis-allocation of VWM resources toward threat-related distractors could be observed in the posterior parietal cortex, dorsolateral prefrontal cortex, and fusiform face area. They proposed that this mis-allocation of memory resources was driven by increased amygdala reactivity to threat in highly anxious individuals. In both of these fMRI studies, however, the paradigms were not designed to differentiate between attentional control-related processes and VWM maintenance.

Although the CDA has been used to track unnecessary storage following filtering, it does not directly reflect the activity associated with attentional selection and distractor filtering (although for evidence of distractor suppression in the closelyrelated $\mathrm{CDA}_{\mathrm{P}}$, see Feldmann-Wüstefeld \& Vogel, 2019). Indeed, there is evidence that once accounting for filteringrelated activity, unnecessary storage no longer predicts VWM performance (Emrich \& Busseri, 2015). Additionally, the temporal limitations of fMRI make it difficult to examine quick shifts in attention that may later bias memory. Therefore, although these studies demonstrate that VWM resources are mis-allocated, how they are mis-allocated (whether by attentional enhancement or suppression) remains unclear.

Given the anxiety-related biases in attentional capture and suppression of threatening stimuli, we predicted that deficits in attentional control drive the mis-allocation of VWM resources toward threat-related distractors. In particular, we hypothesized that anxiety would correlate most strongly with attentional enhancement (i.e. N2pc) of a threatening distractor, which is then stored in VWM. However, this model has not been directly tested in a VWM task with threat-related targets and distractors. Here, we aimed to examine the relationship between anxiety, attentional selection and/or suppression, and VWM maintenance using a combination visual search and VWM task with fearful and neutral faces. One face was always defined as the target, and the other as a distractor, by the color of its surrounding border. Participants were required to hold the target face in VWM to determine whether the face identity changed after a brief delay. To disentangle the N2pc from the $\mathrm{P}_{\mathrm{D}}$, we used a systematic lateralization procedure for stimuli presentation (see Methods). In brief, this procedure allowed us to isolate brain activity related solely to the face presented on the lateral, unaffected by the vertically presented item. Therefore, we could examine target and distractorspecific processing in a task that requires simultaneous presentation. 
If the increase in VWM storage of threatening information in anxiety is due to overall impaired attentional control abilities, then there should be an increased N2pc and decreased $\mathrm{P}_{\mathrm{D}}$ toward fearful face distractors for individuals with high anxiety. But, if increased storage is due primarily to attentional capture of the threat-related distractor, then anxiety should only correlate with $\mathrm{N} 2 \mathrm{pc}$ amplitude. We also predicted that individuals with higher anxiety would have an increased CDA for threatening distractors compared to neutral distractors. Finally, there should be a correlation between the magnitude of one's attentional control deficit and the unnecessary storage of threatening distractors.

\section{Methods}

Some of the methods and analyses of the present study were pre-registered at https://aspredicted.org/cf7jn.pdf.

\section{Participants}

Sixty undergraduate students participated for either course credit or monetary compensation $(\$ 15 / \mathrm{h})$. All participants provided written, informed consent before the experiment began. Procedures were approved by and conducted in accordance with the Brock University Bioscience Research Ethics Board. We aimed to stop data collection once we reached a sample of 48 participants after data rejection (right-handed, normal color vision, no history of mental illness or neurological disorder), although this goal was not reached due to the number of participants rejected and time constraints on data collection. Ten participants' data were excluded due to ocular EEG artifacts on more than $35 \%$ of trials, and four were excluded due to recording errors during the experimental session. The final sample consisted of 46 participants (ten male, $M_{\text {age }}=20.8$ years, $S D_{\text {age }}=3.52$ ).

\section{Apparatus}

All tasks, including the anxiety questionnaires, were completed on a Windows PC with a 41-cm NEC MultiSync LCD 2090UXi monitor (1,600 x 1,200 pixels, 60-Hz refresh rate). Tasks were programmed and presented using Psychopy v1.90.3 (Peirce, 2009) with a viewing distance of approximately $57 \mathrm{~cm}$.

\section{Anxiety scores}

Participants completed both the state and trait anxiety inventories on the computer (STAI; Spielberger, Gorsuch, Lushene, \& Vagg, 1983). These questionnaires have high internal consistency (Cronbach's $\alpha=0.91$ state, 0.90 trait) and test-retest stability ( $r=0.70$ state, 0.88 trait; Barnes, Harp, \& Jung,
2002). Each questionnaire consisted of 20 questions on a 4point Likert scale measuring how anxious the individual was in the moment (e.g., I feel nervous) and in general (e.g., I worry too much over something that really does not matter). Both scales have a minimum score of 20 and maximum of 80 . In the present sample, both state scores $(M=34.39, S D=9.28$, range $=20-63)$ and trait scores $(M=40.46, S D=9.35$, range $=27-64$ ) were similar to norms for undergraduate samples (Spielberger et al., 1983; Stout et al., 2013). State and trait anxiety were significantly correlated, $r=.48, p<$ $.001, \mathrm{BF}_{10}=40.46$.

\section{Face stimuli}

The face images used in the present study were the same as used in Stout, Shackman, and Larson (2013). There was a total of 52 equal luminance black and white faces $\left(2^{\circ}\right.$ wide $\times 2.5^{\circ}$ tall), half fearful and half neutral, with all non-facial features removed. On each trial, there was one face presented on the vertical and another on the lateral midline ( $3^{\circ}$ from fixation). A red $\left(\sim 29.4 \mathrm{~cd} / \mathrm{m}^{2}\right)$ or blue $\left(\sim 11.9 \mathrm{~cd} / \mathrm{m}^{2}\right)$ border surrounded either of the two faces ( 7 pixels wide). Opposite the face images, there were scrambled face images surrounded by a grey border $\left(\sim 15.4 \mathrm{~cd} / \mathrm{m}^{2}\right)$.

\section{Procedures}

Participants first completed a standard visual working memory change-detection task (Luck \& Vogel, 1997; see Online Supplementary Materials). Following EEG cap set up, participants performed a rapid eye-fixation training task on the computer (Guzman-Martinez et al., 2009). This task consisted of a circle containing a flickering pattern of $50 \%$ black and $50 \%$ white pixels (37.5 Hz, $13.3 \mathrm{~ms} /$ frame). Participants were instructed to maintain fixation on a cross ( 24 pixels wide) in the center of the circle and to not move their eyes or blink. When the eyes remain stationary, the flickering pattern subjectively appears grey, but the grey screen becomes disrupted when the eyes are moved such that the pattern is perceived to 'pop out' at the observer. Participants were informed that every time they saw the pattern jump this meant they had moved their eyes, and that they should try to maintain the grey color by minimizing eye movements. Each trial lasted $5 \mathrm{~s}$ and was initiated by any key press. Participants completed trials until they could consistently maintain the grey color by self-report (approximately $2.5 \mathrm{~min}$ ).

Next, participants completed a systematically lateralized change detection task with fearful and neutral faces (see Fig. 1). Participants were told to find and remember the target face, defined by the color of the box surrounding the face (red or blue, counterbalanced across participants). Each trial began with a fixation screen (fixation dot of $3^{\circ}$ diameter; $500-1,500 \mathrm{~ms})$ followed by the search array $(100 \mathrm{~ms})$. The 


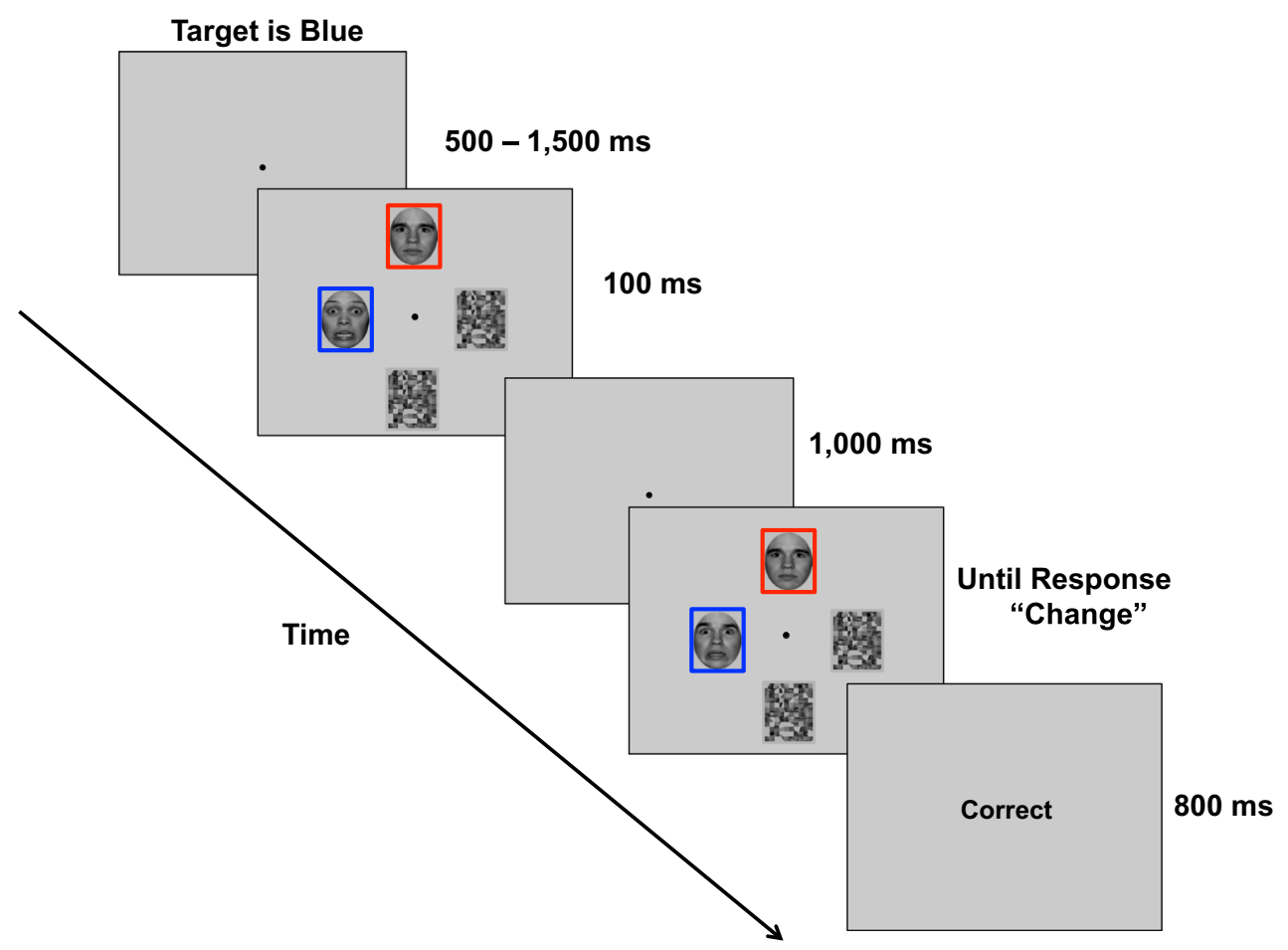

Fig. 1 Task schematic for the lateralized visual working memory face change detection task. Participants were instructed at the beginning of the task which color would be their target color (blue in this example). Participants then must locate the face within a border of the target color

search array consisted of two faces that were either fearful or neutral in expression, with one face on the lateral (left or right of fixation) and the other on the vertical midline (top or bottom). Positions opposite the faces contained scrambled face images that served to balance the visual display. In this design, the face presented on the vertical midline elicits equivalent contralateral and ipsilateral activity and is therefore cancelled out in the difference waveform. We used this lateralized search array so that we could observe the target and distractor specific $\mathrm{N} 2 \mathrm{pc}, \mathrm{P}_{\mathrm{D}}$, and CDA (Feldmann-Wüstefeld \& Vogel, 2019; Hickey et al., 2006, 2009; Woodman \& Luck, 2003).

There were six conditions defined by the Emotion and Relevance (target/distractor) of the lateral face: (1) lateral target fearful face/vertical distractor neutral face, (2) lateral target neutral face/vertical distractor fearful face, (3) lateral target neutral face/vertical distractor neutral face (baseline target condition), and (4-6) the same as conditions 1-3 except with distractors on the lateral. Emotion and Relevance were counterbalanced across all possible position combinations.

After the search display, there was a delay period $(1,000 \mathrm{~ms})$ followed by the response screen, which consisted of two faces in the same positions as in the search array. The participants' goal was to determine whether the face surrounded by the target color changed (50\% of trials) or stayed the same between initial presentation and the probe array. The distractor face always stayed the same. Participants were instructed to and hold the face in memory over a brief delay. A probe screen is then presented where the participant responds whether the target face changed identity ( $50 \%$ of trials) or stayed the same

press the ' $Z$ ' key to indicate a change had occurred or the ' $M$ ' key for no change. After a response was made, accuracy feedback was provided $(800 \mathrm{~ms})$. There was a total of 624 trials: 208 Fear Lateral/Neutral Vertical (104 fear target, 104 fear distractor), 208 Neutral Lateral/Fear Vertical (104 neutral target, 104 neutral distractor), and 208 Neutral Lateral/Neutral Vertical (neutral baseline condition; 104 lateral target, 104 lateral distractor).

\section{EEG recording and pre-processing}

EEG was DC recorded at $512 \mathrm{~Hz}$ using a $64 \mathrm{Ag} / \mathrm{AgCl}$ electrode cap at the standard 10-20 sites (ActiveTwo system; BioSemi, Amsterdam, The Netherlands). The signal was online referenced to common-mode sense and driven right leg electrodes. Pre-processing was completed in MATLAB with EEGLAB (Delorme \& Makeig, 2004) (version 14.0.0b) and ERPLAB (Lopez-Calderon \& Luck, 2014) (version 6.1.2) toolboxes and custom scripts. Data were re-referenced offline to the average of the mastoids and filtered with a $0.01-40 \mathrm{~Hz}$ Butterworth band-pass filter (slope: $12 \mathrm{~dB} /$ octave). Baseline correction was performed from -200 to $0 \mathrm{~ms}$ relative to the search array onset, and epochs were created between -200 and $1,100 \mathrm{~ms}$, time-locked to the search array.

Horizontal electro-oculogram (HEOG) was measured from bipolar external electrodes placed laterally beside each eye. Vertical electro-oculogram (VEOG) was recorded as the 
difference between external electrodes placed below the eyes and activity at FP1 or FP2. Trials with HEOG activity $\pm 32 \mu \mathrm{V}$ and/or VEOG activity $\pm 80 \mu \mathrm{V}$ between search array onset and the end of the trial were rejected. Additionally, any trials with voltage $\pm 100 \mu \mathrm{V}$ over the posterior channels (P1/2, P3/4, P5/ 6, $\mathrm{P} 7 / 8, \mathrm{P} 9 / 10, \mathrm{PO} 3 / \mathrm{O} 4, \mathrm{PO} 7 / \mathrm{O} 8$, and $\mathrm{O} 1 / 2$ ) were removed. Average residual HEOG activity from 0 to $400 \mathrm{~ms}$ was $1.91 \mu \mathrm{V}(S D=1.48 \mu \mathrm{V})$, and from 400 to $1,100 \mathrm{~ms}$ was $3.27 \mu \mathrm{V}(S D=2.76 \mu \mathrm{V})$. Individuals did not make larger saccades toward the lateral fearful face than to the lateral neutral face during either an early $(0-400 \mathrm{~ms})$ or later $(400-1,100$ $\mathrm{ms}$ ) time window (see Online Supplementary Materials).

Participants whose data had $>35 \%$ of total trials rejected were replaced $(\mathrm{N}=10)$. In the final data set, an average of $12.16 \%$ of trials were rejected $(S D=9.05 \%)$. Both correct and incorrect trials were included in the grand average waveforms, consistent with previous studies of similar design (Stout et al., 2013). Mean contralateral minus ipsilateral activity was measured at channel pair PO7/PO8 for each participant and condition, resulting in 6 grand averaged waveforms. All ERP measurements were taken from the difference waveforms as mean amplitudes. To quantify the N2pc, we collapsed across condition and measured negative peak latency between 200 and $300 \mathrm{~ms}$ at channel pair PO7/PO8 in the lateral target waveform for each participant (Feldmann-Wüstefeld \& Vogel, 2019). Then, we averaged across participants and measured N2pc amplitude as $\pm 50 \mathrm{~ms}$ from that peak. Therefore, $\mathrm{N} 2 \mathrm{pc}$ amplitude was measured as the mean amplitude between 210-310 ms.

For the $\mathrm{P}_{\mathrm{D}}$, upon examining the lateral distractors grand average waveform (regardless of emotion), we did not observe a clear positivity in the proposed time range of $200-375 \mathrm{~ms}$; therefore, we chose to not analyze the $\mathrm{P}_{\mathrm{D}}$ (see Discussion). Consistent with previous studies (Feldmann-Wüstefeld \& Vogel, 2019; Ikkai et al., 2010; McCollough et al., 2007), the CDA was measured as the mean amplitude during the delay period (400-1,100 ms).

\section{Data analysis}

All statistical analyses were completed using JASP Version 0.12 (JASP Team, 2020), SPSS Version 25.0 (IBM Corp., Armonk, NY, USA, 2017), and custom scripts in MATLAB R2017a. Behavioral responses were analyzed for accuracy (proportion correct) and sensitivity (Böckmann-Barthel, 2017) between the three main target emotion conditions (fear target/neutral distractor, neutral target/fear distractor, and neutral target/neutral distractor).

For the ERP analyses, we excluded any individual participant component amplitudes that were \pm 3 SDs away from the mean in any condition (and any difference scores created from that condition). However, results did not change when outliers were included in the analyses. For each ERP component of interest, one-way repeated-measures ANOVAs were run separately for the lateral target and distractor conditions. Each ANOVA had three levels defined by the combination of the lateral and midline face emotions (Fear Lateral/Neutral Midline, Neutral Lateral/Fear Midline, and Neutral Lateral/ Neutral Midline). A priori planned contrasts were run where appropriate. Greenhouse-Geisser corrected degrees of freedom and $\mathrm{p}$-values are reported wherever sphericity is violated. P-values for all post hoc tests are Bonferroni-corrected and two-tailed. Bayes Factors (BFs) for repeated-measures ANOVAs and contrasts are reported where applicable ( $\mathrm{r}$ scale prior width of 0.5 , default Cauchy prior centered on $0,10,000$ Monte Carlo samples).

\section{Results}

\section{Behavior}

Accuracy was above chance across all participants and conditions $(M=75 \%, S D=7.7 \%$, range $=57.7-91.2 \%)$. There was a significant effect of target Emotion on accuracy, $F(2,90)=$ 9.23, $p<.001, \eta_{\mathrm{p}}^{2}=.18, \mathrm{BF}_{10}=105.72$, such that changes to a fearful target were detected more accurately $(M=76.4 \%$, $S D=7.5 \%)$ than to the neutral baseline target $(M=74.1 \%, S D$ $\left.=8.1 \%, t(45)=2.99, p_{\text {bonf }}=.01, \mathrm{~d}=.42, \mathrm{BF}_{10}=7.81\right)$. Accuracy for a neutral target in the presence of a fearful distractor $(M=73.2 \%, S D=8.8 \%)$ was not significantly different from a neutral baseline target, $t(45)=1.15, p_{\text {bonf }}=.77, \mathrm{~d}$ $=.17, \mathrm{BF}_{10}=0.30$.

The same pattern of results was observed for measures of sensitivity, such that there was a main effect of target Emotion on d', $F(2,90)=7.03, p=.001, \eta^{2} \mathrm{p}=.32, \mathrm{BF}_{10}=$ 19.81. Overall, participants were more sensitive in detecting changes to fearful target faces $(M=1.95, S D=0.49)$ than to a neutral target face in the presence of a neutral distractor $(M$ $=1.82, S D=0.50, t(45)=3, p_{\text {bonf }}=.013, \mathrm{~d}=.44, \mathrm{BF}_{10}=$ 37.36). Once again, there was not a significant difference in sensitivity between the neutral target/fearful distractor $(M=$ $1.80, S D=0.53)$ and the neutral target/neutral distractor conditions, $t(45)=0.26, p_{\text {bonf }}=1, \mathrm{~d}=.04, \mathrm{BF}_{10}=0.17$. Neither state or trait anxiety was correlated with accuracy or sensitivity in any Emotion condition, $r \mathrm{~s}<.22, p \mathrm{~s}>.14$. This suggests that individuals with higher anxiety levels were performing the task as accurately as less anxious individuals.

\section{Electrophysiology}

N2pc. Contralateral and ipsilateral waveforms for all conditions can be seen in Fig. 2A-F. When the target was presented laterally, there was no effect of face configuration on the amplitude of the N2pc, $F(2,90)=0.87, p=.423, \eta_{\mathrm{p}}^{2}=.02, \mathrm{BF}_{10}$ 
Table 1 Descriptive statistics for N2pc and CDA amplitudes by condition

\begin{tabular}{|c|c|c|c|c|}
\hline \multirow[t]{2}{*}{ Condition } & \multicolumn{2}{|l|}{$\mathrm{N} 2 \mathrm{pc}(\mu \mathrm{V})$} & \multicolumn{2}{|l|}{$\mathrm{CDA}(\mu \mathrm{V})$} \\
\hline & $M(S D)$ & $95 \% \mathrm{CI}$ & $M(\mathrm{SD})$ & $95 \% \mathrm{CI}$ \\
\hline \multicolumn{5}{|c|}{ Target Lateral/Distractor Midline } \\
\hline Fear/Neutral & $-1.78(1.72)$ & {$[-2.25,-1.30]$} & $-1.22(1.52)$ & {$[-1.64,-0.81]$} \\
\hline Neutral/Fear & $-1.51(1.63)$ & {$[-1.98,-1.03]$} & $-1.08(1.41)$ & {$[-1.49,-0.66]$} \\
\hline Neutral/Neutral & $-1.53(1.51)$ & {$[-2.00,-1.05]$} & $-0.93(1.34)$ & {$[-1.35,-0.51]$} \\
\hline \multicolumn{5}{|c|}{ Distractor Lateral/Target Midline } \\
\hline Fear/Neutral & $-0.98(1.38)$ & {$[-1.34,-0.61]$} & $-0.38(1.09)$ & {$[-0.73,-0.12]$} \\
\hline Neutral/Fear & $-0.42(1.23)$ & {$[-0.79,-0.06]$} & $-0.15^{\mathrm{a}}(0.92)$ & {$[-0.73,-0.12]$} \\
\hline Neutral/Neutral & $-0.37(1.13)$ & {$[-0.74,0.01]$} & $0.12(1.10)$ & {$[-0.22,0.39]$} \\
\hline
\end{tabular}

${ }^{\mathrm{a}}$ All $n \mathrm{~s}=46$ except for noted condition wherein $n=45$ due to outlier removal

$=0.15$ (Fig. $3 \mathrm{~A} 1$ and $\mathrm{A} 2$; see Table 1 for descriptive statistics). There was, however, an effect of face configuration when the distractor was presented laterally, $F(1.7,76.4)=$ $5.54, p=.008, \eta_{\mathrm{p}}^{2}=.11, \mathrm{BF}_{10}=6.63$ (Fig. 3B1 and $\mathrm{B} 2$ ). Planned contrasts revealed that there was a greater N2pc to the lateral fear distractor than to the neutral baseline distractor, $t(90)=2.99, p=.004, \mathrm{BF}_{10}=2.94$. Comparing the two conditions where a neutral face was presented laterally, there was no significant difference in N2pc amplitude, $t(90)=0.23, p=$ $.816, \mathrm{BF}_{10}=0.17$. These findings suggest that averaged across individuals, threat-related distractors captured attention more than neutral distractors.

CDA. When the target was presented laterally, face configuration did not have a significant effect on CDA amplitude, $F(2,90)=0.64, p=.531, \eta_{\mathrm{p}}^{2}=.01, \mathrm{BF}_{10}=0.12$ (see Table 1 for descriptive statistics). Similarly, when the distractor was on the lateral, CDA amplitude did not significantly differ between the three face configurations, $F(2,90)=2.71, p=.072, \eta_{\mathrm{p}}^{2}=.06, \mathrm{BF}_{10}=0.99$. Based on the prediction that CDA amplitude would be greater for lateral fearful faces than for neutral faces, we examined planned contrasts for both targets and distractors. CDA amplitude was not significantly greater for the lateral fear target than the neutral baseline target, $t(90)=$ $1.13, p=.262, \mathrm{BF}_{10}=0.26$. However, CDA amplitude was greater for the fear distractor than the neutral baseline distractor, $t(88)=2.32, p=.023, \mathrm{BF}_{10}=1.4$. This provides weak evidence that participants were holding the fearful distractor in memory more often than the neutral distractor.

$\mathrm{N} 2 \mathrm{pc}$ and CDA correlations. To test whether changes in attention allocation to fearful versus neutral faces led to greater memory storage of those fearful faces, we created $\mathrm{N} 2 \mathrm{pc}$ and CDA difference scores between the Fear
Lateral/Neutral Midline and Neutral Lateral/Neutral Midline conditions for both lateral targets and distractors. N2pc amplitude correlated positively with CDA amplitude for fearful versus neutral targets, $r=.725, p<$ $.001, \mathrm{BF}_{10}=1.25^{6}$, and fearful versus neutral distractors, $r=.605, p<.001, \mathrm{BF}_{10}=2,159$. These findings demonstrate that the more an individual paid attention to the fearful target or distractor, the more likely that face was to be held in memory, regardless of their level of anxiety.

\section{Anxiety predicts attention toward a fearful face distractor}

To determine how anxiety affected attention toward a distracting threat-related face, we examined mean N2pc amplitude difference scores between the fearful distractor face and the neutral distractor baseline condition (i.e., Neutral distractor lateral/Neutral target midline). More negative scores indicate a larger $\mathrm{N} 2 \mathrm{pc}$ toward the fearful than to the neutral distractor. It was found that more anxious individuals had greater N2pc amplitudes toward a fearful distractor compared to the neutral baseline distractor, $r(44)=-.35, p=.018,95 \%$ CI [-.58, -.06], $\mathrm{BF}_{10}=2.76$ (Fig. 4A). In contrast, there was no correlation between state anxiety and N2pc amplitude toward a lateral fearful target compared to the neutral baseline target, $r(45)=.15, p=.333,95 \% \mathrm{CI}[-.15, .42], \mathrm{BF}_{10}=$ 0.29 (Fig. 4B).

To examine whether the relationship between anxiety and $\mathrm{N} 2 \mathrm{pc}$ amplitude was specific to threat-related distractors, we also analyzed amplitude difference scores between the lateral neutral/vertical fearful condition and the neutral baseline condition (for both targets and distractors). More negative scores indicate greater attention toward the neutral face in the presence of the fearful one, than to the neutral face in the baseline condition. In contrast to when fearful faces were presented laterally, state anxiety scores did not predict greater N2pc 
Target Lateral
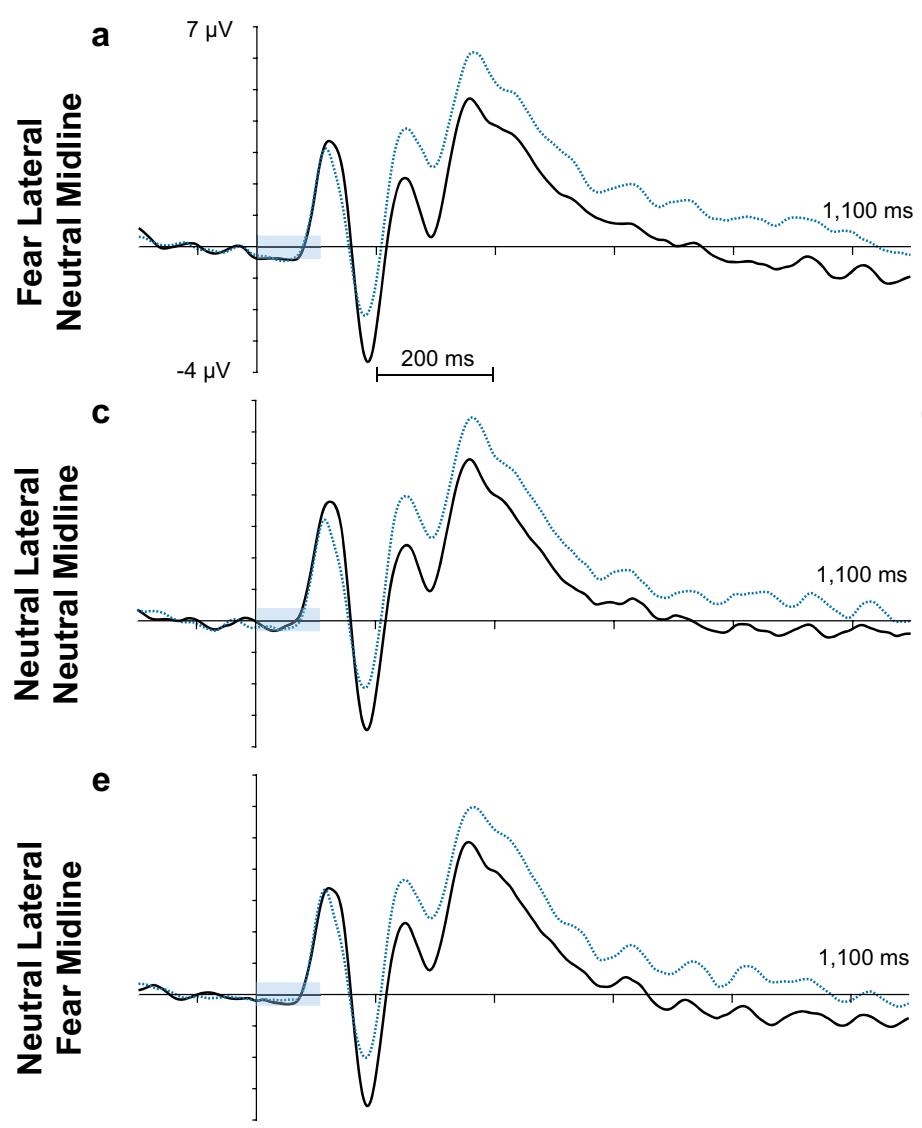

Fig. 2 Contralateral (black solid lines) and ipsilateral (blue dashed lines) waveforms at channel pair PO7/PO8 for each condition. Filtered at $30 \mathrm{~Hz}$ for illustrative purposes only. Y-axis scales are the same for all sub-

amplitudes toward lateral neutral faces in either the target, $r(45)=-.06, p=.685,95 \%$ CI $[-.35, .23], \mathrm{BF}_{10}=0.2$, or distractor conditions, $r(45)=-.273, p=.067,95 \%$ CI $[-.52$, $.02], \mathrm{BF}_{10}=0.94$. There were no significant correlations between $\mathrm{N} 2 \mathrm{pc}$ amplitudes and trait anxiety in the same comparisons, $r \mathrm{~s}<.19, p \mathrm{~s}>.21, \mathrm{BFs}_{10}<0.38$. When including residual HEOG as a covariate, the pattern of results did not change (see Online Supplementary Material, Results). Therefore, our findings suggest that individuals with greater state anxiety levels are only biased toward fearful faces when they are distractors and not when they are targets, and that this bias does not extend to neutral distractors.

\section{Anxiety does not predict memory storage of a distracting fearful face}

To examine the correlation between VWM storage and anxiety we created mean amplitude CDA difference scores for the same conditions as was done for the N2pc (i.e., lateral fearful minus lateral neutral baseline). In contrast to previous findings (Qi et al., 2014; Stout et al., 2013), we did not observe a correlation between CDA amplitudes and anxiety. State
Distractor Lateral

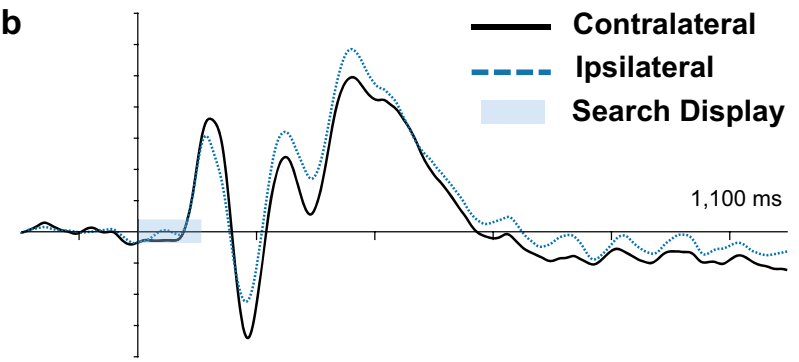

d

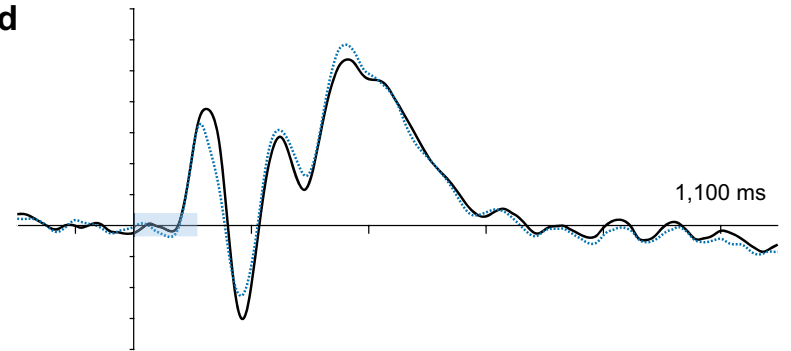

$\mathbf{f}$

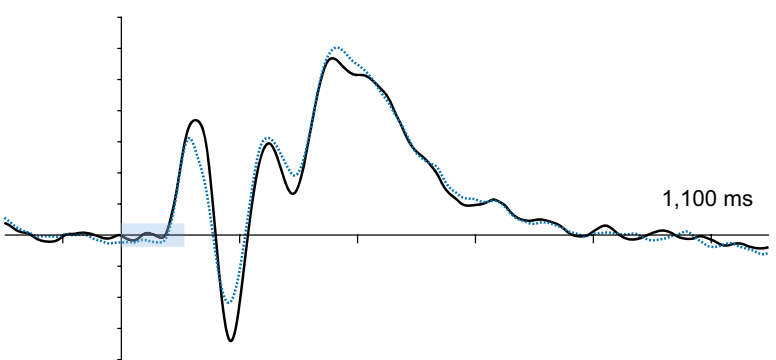

figures. (A) Fear Lateral/Neutral Midline target and (B) distractor conditions. (C) Neutral Baseline target and (D) distractor conditions. (E) Neutral Lateral/Fear Midline target and (F) distractor conditions

anxiety did not predict greater CDA amplitude for a lateral fearful target, $r(45)=.203, p=.176,95 \%$ CI [-.06, .47], $\mathrm{BF}_{10}$ $=0.45$, or for a fearful distractor, $r(45)=-.199, p=.184,95 \%$ CI $[-.46, .1], \mathrm{BF}_{10}=0.43$. State anxiety also did not correlate with memory storage of a neutral target in the presence of a fearful distractor, $r(45)=.105, p=.489,95 \%$ CI $[-.19, .38]$, $\mathrm{BF}_{10}=0.23$, or a neutral distractor in the presence of a fearful target, $r(44)=-.215, p=.152,95 \% \mathrm{CI}[-.48, .08], \mathrm{BF}_{10}=0.50$. There were also no correlations between trait anxiety and CDA amplitudes in these same comparisons, $r \mathrm{~s}<.17, p \mathrm{~s}>$ $.26, \mathrm{BFs}_{10}<0.34$. Overall, these results suggest that in this task, anxiety does not predict greater memory storage of a threat-related compared to a neutral face, whether that face is a target or a distractor.

\section{Discussion}

In the present study, we aimed to examine how anxiety biases attentional enhancement $(\mathrm{N} 2 \mathrm{pc})$, distractor suppression $\left(\mathrm{P}_{\mathrm{D}}\right)$, and VWM storage (CDA) of threat-related distractors. We found that across all individuals, regardless of anxiety level, 

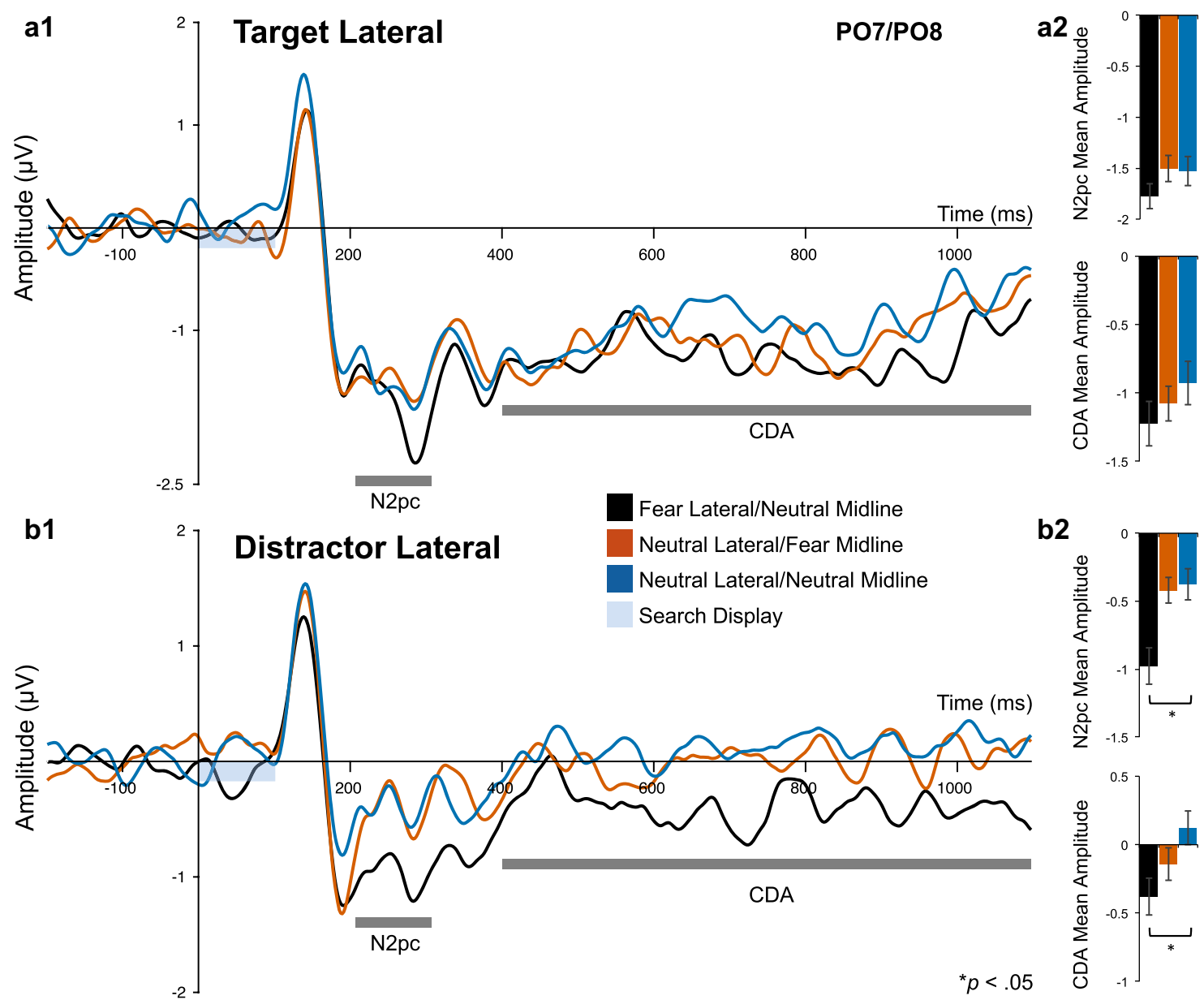

Fig. 3 Grand average difference waveforms $(\mathrm{N}=46)$ measured at channel pair PO7/PO8, time-locked to stimuli onset. Filtered at $30 \mathrm{~Hz}$ for illustrative purposes only. (A1) Waveforms for target lateral conditions. (A2) Bar graphs of mean N2pc and CDA amplitudes by target lateral condition. Within-subject error bars reflect \pm 1 SEM. (B1) Waveforms for distractor lateral conditions. (B2) Bar graphs of mean $\mathrm{N} 2 \mathrm{pc}$ and CDA amplitudes by distractor lateral condition. Withinsubject error bars reflect \pm 1 SEM

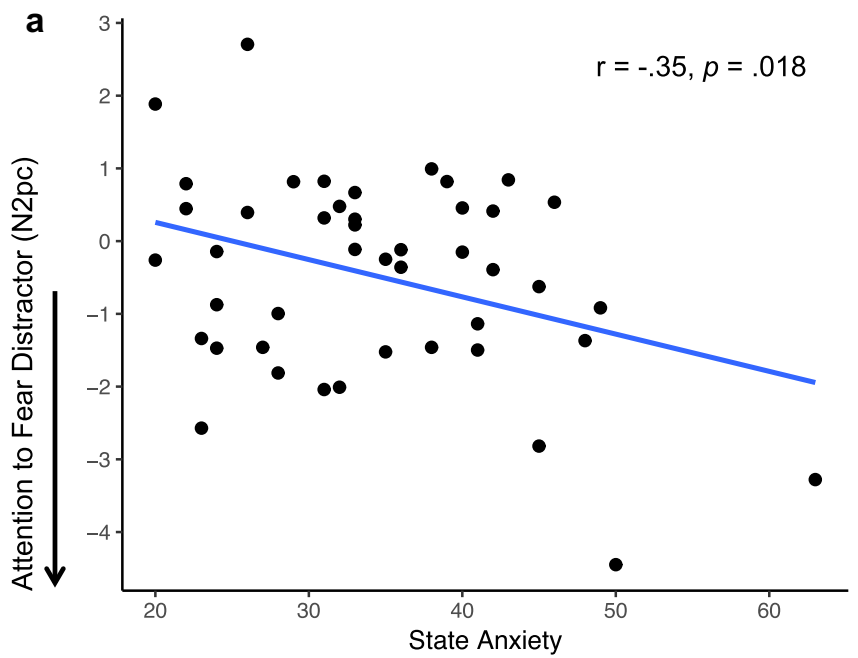

Fig. 4 Scatterplots between state anxiety scores and mean N2pc amplitudes. (A) Greater state anxiety correlates with greater N2pc amplitudes toward a lateral fearful face distractor compared to a lateral neural distractor (difference score). More negative scores indicate greater

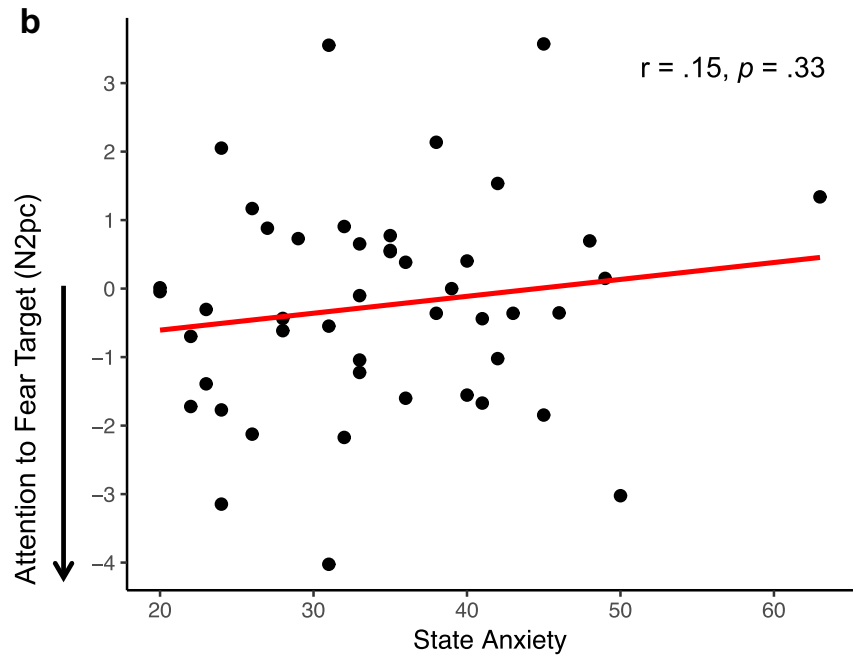

attention toward the fearful face distractor than the neutral baseline distractor. (B) Greater state anxiety does not correlate with N2pc amplitude toward a fearful face target compared to the neutral baseline target (difference score) 
there were significantly larger N2pc and CDA amplitudes toward fearful distractors than neutral distractors. However, when the fearful face was a target (i.e., task relevant), it was not attended to or remembered more often than a neutral target. These findings are consistent with a large body of literature that suggests that threat-detection of fear-related stimuli is automatic (LeDoux, 2000; Öhman, 2005). This bottom-up capture by threat-related faces is likely driven by the amygdala, which subsequently biases activity in the fusiform face area, prefrontal, and parietal cortices (Öhman, 2005; Stout et al., 2017). Individuals with higher levels of anxiety have amplified amygdala reactivity, resulting in greater attentional biases toward threat-related information than their less anxious counterparts (Shackman et al., 2016; Stout et al., 2017). This is in agreement with our finding that individuals who had higher state anxiety also had larger N2pc amplitudes toward fearful distractors than neutral distractors. Therefore, the present study supports the idea that individuals with anxiety have an attentional bias toward task-irrelevant, threat-related information; caused by both impaired top-down cognitive control and increased attentional guidance by bottom-up stimuli salience (Eysenck et al., 2007).

Yet, inconsistent with prior studies, we did not find that $\mathrm{N} 2 \mathrm{pc}$ and CDA amplitudes were larger for threat-related compared to neutral targets. For example, Feldmann-Wüstefeld et al. (2011) found that these two ERP components were larger for angry targets compared to happy targets. Similarly, Stout et al. (2013) found larger CDA amplitudes for two fearful face targets than for two neutral targets. These studies differ from the present one in that they presented several faces on the lateral, both neutral and emotional (but, see Sessa et al., 2011). Here, only a single target was presented laterally, such that even if the face were remembered, the CDA amplitude for that one item would be quite small overall. Therefore, the present effect sizes may be too small to distinguish between the target conditions.

Contrary to our hypotheses, anxiety levels did not correlate with CDA amplitude toward fearful distractors, suggesting that anxious individuals had an attentional bias toward threatening distractors, but did not necessarily hold that irrelevant information in memory. This finding is at odds with several studies that have found poor distractor filtering of threat in anxiety, as measured by the CDA (e.g., Sessa et al., 2011; Stout et al., 2013). This discrepancy could be explained by differences in methodological design, as in these previous studies the face stimuli were presented for at least $200 \mathrm{~ms}$, compared to the $100 \mathrm{~ms}$ used here. We may have only observed an early attentional bias, and not a memory bias, because memory storage of faces requires a longer encoding time (Curby \& Gauthier, 2007).

There are several additional methodological differences between the present study and prior experiments, which may in part explain discrepancies from previous findings. For example, some studies used all fearful or neutral faces in the display without different emotion distractors (Kiss \& Eimer, 2008; Sessa et al., 2011). Others did not have a condition where a fearful target was presented with a neutral distractor (Stout et al., 2013), or a neutral target condition (FeldmannWüstefeld et al., 2011). Studies also differ by type of face stimuli used, such as schematic faces (Weymar et al., 2011) or angry faces (Burra et al., 2016; Holmes et al., 2009). Participant strategy is also likely affected by the task, whether that be a speeded visual search task (Feldmann-Wüstefeld et al., 2011), or an un-speeded VWM task, such as is used here. Future studies should closely consider the influence of task design and stimuli parameters to better synthesize the literature on anxiety and threat-related filtering.

Deficits in attentional control have been consistently observed in individuals with high trait anxiety (Fox et al., 2008; Gaspar \& McDonald, 2018; Qi et al., 2014; Stout et al., 2013). Yet, here we found a correlation with state anxiety only. This could be due to an absence of participant pre-screening, however, given that state and trait anxiety were highly correlated, the limited range of the sample cannot fully explain the absence of a correlation between trait anxiety and N2pc amplitudes. There is also evidence that state anxiety is correlated with amygdala reactivity to threat, regardless of whether the threat was attended or unattended, whereas trait anxiety has a greater influence on prefrontal attentional control (Bishop, 2009; Bishop, Duncan, \& Lawrence, 2004b; Bishop et al., 2007). Therefore, in a task that does not require a lot of cognitive control (such as in the present study), we would expect to observe a greater effect of state anxiety on amygdala reactivity to fearful stimuli than trait anxiety's impact on top-down attentional control.

Beyond biased attentional selection of fearful distractors, we also predicted that attentional control deficits would emerge as impaired active suppression of irrelevant threatening stimuli, as measured by the $\mathrm{P}_{\mathrm{D}}$. However, we could not test this hypothesis, as we did not observe a clear $\mathrm{P}_{\mathrm{D}}$ component in the distractor waveforms. It could be that because only one distractor was present, the distractor was easy to ignore without needing an active suppression process. Indeed, there is evidence that the $\mathrm{P}_{\mathrm{D}}$ amplitude increases with the number of lateralized distractors in a VWM task (Feldmann-Wüstefeld \& Vogel, 2019) and with perceptual load (Bretherton et al., 2017). However, even with multiple distractors the $P_{D}$ is quite small (Feldmann-Wüstefeld \& Vogel, 2019).

Another possibility for the absence of a $\mathrm{P}_{\mathrm{D}}$ is that the grand average waveform was overall more negative than is usually observed in lateralized visual search tasks. Therefore, if a more positive-going potential were to have occurred following the N2pc, from around $300-400 \mathrm{~ms}$, it would still be measured as negative-going (although this does not appear to be the case from visual inspection of the grand average waveform). This overall increased negativity of the grand 
average waveform seemed to be driven by a negative-going component occurring directly before the N2pc in the time range of 170-200 ms. This negativity could reflect a lateralized N170, a component that reflects the encoding of faces more than non-face stimuli (Bentin et al., 1996; Eimer, 2000). However, there is evidence that the N170 is not affected by selective attention (Cauquil et al., 2000), and therefore its presence should not affect later attention and memoryrelated components such as the N2pc and CDA.

There was also a lateralized positivity present in the time range of the $\mathrm{P} 1$, suggesting that despite our procedures to balance sensory differences, some overall physical imbalances in the display remained. This imbalance was likely due to our use of scrambled faces as a sensory balance (unlike the masks used by Kiss and Eimer, 2008). This positivity could also reflect an early $\mathrm{P}_{\mathrm{D}}$ (also referred to as the Ppc; FortierGauthier et al., 2012; Jannati et al., 2013; Luck \& Hillyard, $1994 b)$. Because the positivity was equivalent in amplitude across all conditions, $F(4.19,188.43)=1.91, p=.107$, however, it most likely does not reflect early suppression. Instead, it could indicate pre-attentive activation of the salience map, which is used to guide subsequent attention (Jannati et al., 2013). However, as this component was not the focus of the present study, further research is required to determine whether the early $\mathrm{P}_{\mathrm{D}}$ influences attentional selection and suppression of emotional stimuli.

Our final hypothesis was that the relationship between anxiety and VWM storage of fearful distractors would be mediated by attentional enhancement of those distractors. However, because CDA amplitude was not correlated with anxiety, we could not test that model. Yet, we did find that averaged across individuals, greater attention toward a fearful face (regardless of task relevance) correlated with memory storage of that face; that is, greater changes in N2pc amplitudes in response to fearful faces resulted in greater changes in CDA amplitudes. If anxiety does not always correlate with VWM storage, this brings into question whether gating deficits are a defining feature of anxiety-related threat processing. When this 'gating deficit' occurs has been inconsistent in the literature, and it is unclear whether gating occurs pre- or postattentional selection. There is evidence that inefficient filtering arises prior to working memory storage, resulting from attentional control processes in the prefrontal cortex and basal ganglia (Liesefeld et al., 2014; McNab \& Klingberg, 2008). Consequently, the N2pc could be a marker of the filtering process itself (Jannati et al., 2013). Regardless of the timing of this gating deficit, we propose that attentional biases, and not memory storage, are the more reliable indicator of an individual's anxious state.

Accordingly, there is evidence that unnecessary storage does not predict VWM performance as well as the preceding attentional control-related brain activity (Emrich \& Busseri, 2015). In addition, several studies have found that a strict all- or-none memory filter (wherein all targets are let into memory and all distractors are denied access) is not sufficient to describe memory performance (Dube et al., 2017; Emrich et al., 2017; Salahub et al., 2019). The ability to flexibly allocate memory resources amongst items may be related to attentional control, a likely candidate for the underlying mechanism driving the relationship between anxiety and the mis-allocation of VWM resources observed in prior studies. Therefore, instead of anxiety causing a threat-related gating deficit, it seems likely that anxiety impairs attentional control abilities, such that threatening irrelevant items receive more enhanced processing than neutral relevant items. To better understand the underlying mechanism of unnecessary VWM storage for threatrelated distractors, future studies should examine how item priority interacts with anxiety.

The present findings support a large body of literature that finds an attentional bias toward threat-related distractors for individuals with anxiety. Here, we found that individuals with anxiety do not always unnecessarily store that attended information in VWM. Instead, we show that anxious individuals have an attentional control deficit, resulting in enhanced selection, and not a failure in suppression, of salient threatrelated distractors.

Acknowledgements This work was supported by Natural Sciences and Engineering Research Council of Canada (NSERC) Discovery (\#2019435945) and Research Tools and Instruments (\#458707) Grants awarded to SME, and a NSERC post-graduate scholarship awarded to CS. We thank Joseph Capozza (experiment programming/data collection) and Brenda de Wit (data collection).

Open practices statement The methods and analyses in the present study were pre-registered at https://aspredicted.org/cf7jn.pdf. The data from this experiment are not available online due to the absence of participant consent. Task and data analysis scripts are available upon request.

Author Contributions CS and SME contributed equally to the experimental design, data analysis, and manuscript preparation. CS collected the data.

\section{Compliance with ethical standards}

Competing interests The authors declare no competing interests.

\section{References}

Ansari, T. L., \& Derakshan, N. (2011). The neural correlates of impaired inhibitory control in anxiety. Neuropsychologia, 49(5), 1146-1153.

Bar-Haim, Y., Lamy, D., Pergamin, L., Bakermans-Kranenburg, M. J., \& Van Ijzendoorn, M. H. (2007). Threat-related attentional bias in anxious and nonanxious individuals: A meta-analytic study. Psychological Bulletin, 133(1), 1-24.

Barnes, L., Harp, D., \& Jung, W. (2002). Reliability generalization of scores on the Spielberger state-trait anxiety inventory. Educational and Psychological Measurement, 62(4), 603-618. https://doi.org/ $10.1177 / 0013164402062004005$ 
Beck, A. T., \& Clark, D. A. (1997). An information processing model of anxiety: Automatic and strategic processes. Behaviour Research and Therapy, 35(1), 49-58. https://doi.org/10.1016/S00057967(96)00069-1

Bentin, S., Allison, T., Puce, A., Perez, E., \& McCarthy, G. (1996). Electrophysiological studies of face perception in humans. Journal of Cognitive Neuroscience, 8(6), 551-565. https://doi.org/10.1162/ jocn.1996.8.6.551

Berggren, N., \& Derakshan, N. (2013). Attentional control deficits in trait anxiety: Why you see them and why you don't. Biological Psychology, 92(3), 440-446.

Bishop, S. J. (2007). Neurocognitive mechanisms of anxiety: An integrative account. Trends in Cognitive Sciences, 11(7), 307-316. https:// doi.org/10.1016/j.tics.2007.05.008

Bishop, S. J. (2009). Trait anxiety and impoverished prefrontal control of attention. Nature Neuroscience, 12(1), 92-98. https://doi.org/10. 1038/nn.2242

Bishop, S. J., Duncan, J., Brett, M., \& Lawrence, A. D. (2004a). Prefrontal cortical function and anxiety: Controlling attention to threat-related stimuli. Nature Neuroscience, 7(2), 184-188. https:// doi.org/10.1038/nn1173

Bishop, S. J., Duncan, J., \& Lawrence, A. D. (2004b). State anxiety modulation of the amygdala response to unattended threat-related stimuli. Journal of Neuroscience, 24(46), 10364-10368. https://doi. org/10.1523/JNEUROSCI.2550-04.2004

Bishop, S. J., Jenkins, R., \& Lawrence, A. D. (2007). Neural processing of fearful faces: Effects of anxiety are gated by perceptual capacity limitations. Cerebral Cortex, 17(7), 1595-1603. https://doi.org/10. 1093/cercor/bhl070

Böckmann-Barthel, M. (2017). r. https://www.mathworks.com/ matlabcentral/fileexchange/65377-sensitivity-index-d

Bretherton, P. M., Eysenck, M. W., Richards, A., \& Holmes, A. (2017). Target and distractor processing and the influence of load on the allocation of attention to task-irrelevant threat. Neuropsychologia. https://doi.org/10.1016/j.neuropsychologia.2017.09.009

Burra, N., Barras, C., Coll, S. Y., \& Kerzel, D. (2016). Electrophysiological evidence for attentional capture by irrelevant angry facial expressions. Biological Psychology, 120, 69-80. https:// doi.org/10.1016/j.biopsycho.2016.08.008

Burra, N., Coll, S. Y., Barras, C., \& Kerzel, D. (2017). Electrophysiological evidence for attentional capture by irrelevant angry facial expressions: Naturalistic faces. Neuroscience Letters, 637, 44-49. https://doi.org/10.1016/j.neulet.2016.11.055

Burra, N., \& Kerzel, D. (2014). The distractor positivity (Pd) signals lowering of attentional priority: Evidence from event-related potentials and individual differences. Psychophysiology, 51(7), 685-696. https://doi.org/10.1111/psyp.12215

Burra, N., Pittet, C., Barras, C., \& Kerzel, D. (2019). Attentional suppression is delayed for threatening distractors. Visual Cognition, 27(34), 185-198. https://doi.org/10.1080/13506285.2019.1593272

Cauquil, A. S., Edmonds, G. E., \& Taylor, M. J. (2000). Is the facesensitive N170 the only ERP not affected by selective attention? NeuroReport, 11(10), 2167-2171.

Curby, K. M., \& Gauthier, I. (2007). A visual short-term memory advantage for faces. Psychonomic Bulletin \& Review, 14(4), 620-628. https://doi.org/10.3758/BF03196811

Delorme, A., \& Makeig, S. (2004). EEGLAB: An open source toolbox for analysis of single-trial EEG dynamics including independent component analysis. Journal of Neuroscience Methods, 134(1), 921. https://doi.org/10.1016/j.jneumeth.2003.10.009

Derakshan, N., \& Eysenck, M. W. (2009). Anxiety, processing efficiency, and cognitive performance. European Psychologist, 14(2), 168 176. https://doi.org/10.1027/1016-9040.14.2.168

Dube, B., Emrich, S. M., \& Al-Aidroos, N. (2017). More than a filter: Feature-based attention regulates the distribution of visual working memory resources. Journal of Experimental Psychology. Human
Perception and Performance, 43(10), 1843-1854. https://doi.org/ $10.1037 / \mathrm{xhp} 0000428$

Eimer. (1996). The N2pc component as an indicator of attentional selectivity. Electroencephalography and Clinical Neurophysiology, 99(3), 225-234.

Eimer, \& Kiss, M. (2007). Attentional capture by task-irrelevant fearful faces is revealed by the N2pc component. Biological Psychology, 74(1), 108-112. https://doi.org/10.1016/j.biopsycho.2006.06.008

Eimer, M. (2000). The face-specific N170 component reflects late stages in the structural encoding of faces. NeuroReport, 11(10), 2319.

Emrich, S. M., \& Busseri, M. A. (2015). Re-evaluating the relationships among filtering activity, unnecessary storage, and visual working memory capacity. Cognitive, Affective, \& Behavioral Neuroscience, 15(3), 589-597. https://doi.org/10.3758/s13415015-0341-z

Emrich, S. M., Lockhart, H. A., \& Al-Aidroos, N. (2017). Attention mediates the flexible allocation of visual working memory resources. Journal of Experimental Psychology. Human Perception and Performance, 43(7), 1454-1465. https://doi.org/10.1037/ xhp0000398

Eysenck, M. W., Derakshan, N., Santos, R., \& Calvo, M. G. (2007). Anxiety and cognitive performance: Attentional control theory. Emotion, 7(2), 336-353.

Feldmann-Wüstefeld, T., Schmidt-Daffy, M., \& Schubö, A. (2011). Neural evidence for the threat detection advantage: Differential attention allocation to angry and happy faces: Neural evidence for threat detection. Psychophysiology, 48(5), 697-707. https://doi. org/10.1111/j.1469-8986.2010.01130.x

Feldmann-Wüstefeld, T., \& Vogel, E. K. (2019). Neural evidence for the contribution of active suppression during working memory filtering. Cerebral Cortex, 29(2), 529-543. https://doi.org/10.1093/cercor/ bhx336

Fortier-Gauthier, U., Moffat, N., Dell'Acqua, R., McDonald, J. J., \& Jolicœur, P. (2012). Contralateral cortical organisation of information in visual short-term memory: Evidence from lateralized brain activity during retrieval. Neuropsychologia, 50(8), 1748-1758. https://doi.org/10.1016/j.neuropsychologia.2012.03.032

Fox, E., Derakshan, N., \& Shoker, L. (2008). Trait anxiety modulates the electrophysiological indices of rapid spatial orienting towards angry faces. Neuroreport, 19(3), 259-263.

Fox, E., Russo, R., Bowles, R., \& Dutton, K. (2001). Do threatening stimuli draw or hold visual attention in subclinical anxiety? Journal of Experimental Psychology: General, 130(4), 681-700. https://doi.org/10.1037/0096-3445.130.4.681

Gambarota, F., \& Sessa, P. (2019). Visual working memory for faces and facial expressions as a useful "tool" for understanding social and affective cognition. Frontiers in Psychology, 10. https://doi.org/10. 3389/fpsyg.2019.02392

Gaspar, J. M., \& McDonald, J. J. (2014). Suppression of salient objects prevents distraction in visual search. Journal of Neuroscience, 34(16), 5658-5666. https://doi.org/10.1523/JNEUROSCI.4161-13. 2014

Gaspar, J. M., \& McDonald, J. J. (2018). High level of trait anxiety leads to salience-driven distraction and compensation. Psychological Science, 29(12), 2020-2030. https://doi.org/10.1177/ 0956797618807166

Gaspelin, N., \& Luck, S. J. (2018). Combined electrophysiological and behavioral evidence for the suppression of salient distractors. Journal of Cognitive Neuroscience, 30(9), 1265-1280. https://doi. org/10.1162/jocn_a 01279

Guzman-Martinez, E., Leung, P., Franconeri, S., Grabowecky, M., \& Suzuki, S. (2009). Rapid eye-fixation training without eyetracking. Psychonomic Bulletin \& Review, 16(3), 491-496. https://doi.org/10. 3758/PBR.16.3.491

Hickey, C., Di Lollo, V., \& McDonald, J. J. (2009). Electrophysiological indices of target and distractor processing in visual search. Journal 
of Cognitive Neuroscience, 21(4), 760-775. https://doi.org/10.1162/ jocn.2009.21039

Hickey, C., McDonald, J. J., \& Theeuwes, J. (2006). Electrophysiological evidence of the capture of visual attention. Journal of Cognitive Neuroscience, 18(4), 604-613. https://doi.org/10.1162/jocn.2006. 18.4.604

Hodsoll, S., Viding, E., \& Lavie, N. (2011). Attentional capture by irrelevant emotional distractor faces. Emotion, 11(2), 346-353. https:// doi.org/10.1037/a0022771

Holmes, A., Bradley, B. P., Nielsen, M. K., \& Mogg, K. (2009). Attentional selectivity for emotional faces: Evidence from human electrophysiology. Psychophysiology, 46(1), 62-68. https://doi.org/ 10.1111/j.1469-8986.2008.00750.x

IBM SPSS Statistics for Macintosh (25.0). (2017). [Computer software]. IBM Corp.

Ikkai, A., McCollough, A., \& Vogel, E. (2010). Contralateral delay activity provides a neural measure of the number of representations in visual working memory. Journal of Neurophysiology, 103(4), 1963-1968.

Jannati, A., Gaspar, J. M., \& McDonald, J. J. (2013). Tracking target and distractor processing in fixed-feature visual search: Evidence from human electrophysiology. Journal of Experimental Psychology: Human Perception and Performance, 39(6), 1713-1730. https:// doi.org/10.1037/a0032251

Kappenman, E. S., MacNamara, A., \& Proudfit, G. H. (2015). Electrocortical evidence for rapid allocation of attention to threat in the dot-probe task. Social Cognitive and Affective Neuroscience, 10(4), 577-583. https://doi.org/10.1093/scan/nsu098

Kiss, M., \& Eimer, M. (2008). ERPs reveal subliminal processing of fearful faces. Psychophysiology, 45(2), 318-326. https://oi.org/ 10.1111/j.1469-8986.2007.00634.x

LeDoux, J. E. (2000). Emotion circuits in the brain. Annual Review of Neuroscience, 23(1), 155-184. https://doi.org/10.1146/annurev. neuro.23.1.155

Liesefeld, A. M., Liesefeld, H. R., \& Zimmer, H. D. (2014). Intercommunication between prefrontal and posterior brain regions for protecting visual working memory from distractor interference. Psychological Science, 25(2), 325-333. https://doi.org/10.1177/ 0956797613501170

Lopez-Calderon, J., \& Luck, S. J. (2014). ERPLAB: An open-source toolbox for the analysis of event-related potentials. Frontiers in Human Neuroscience, 8. https://doi.org/10.3389/fnhum.2014. 00213

Luck, S. J., \& Hillyard, S. A. (1994a). Spatial filtering during visual search: Evidence from human electrophysiology. Journal of Experimental Psychology: Human Perception and Performance, 20(5), 1000-1014. https://doi.org/10.1037/0096-1523.20.5.1000

Luck, S. J., \& Hillyard, S. A. (1994b). Electrophysiological correlates of feature analysis during visual search. Psychophysiology, 31(3), 291308. https://doi.org/10.1111/j.1469-8986.1994.tb02218.x

Luck, S. J., \& Vogel, E. K. (1997). The capacity of visual working memory for features and conjunctions. Nature, 390(6657), 279281. https://doi.org/10.1038/36846

Mathews, A., \& Mackintosh, B. (1998). A cognitive model of selective processing in anxiety. Cognitive Therapy and Research, 22(6), 539560. https://doi.org/10.1023/A:1018738019346

McCollough, A. W., Machizawa, M. G., \& Vogel, E. K. (2007). Electrophysiological measures of maintaining representations in visual working memory. Cortex, 43(1), 77-94.

McNab, F., \& Klingberg, T. (2008). Prefrontal cortex and basal ganglia control access to working memory. Nature Neuroscience, 11(1), 103-107. https://doi.org/10.1038/nn2024

Mogg, K., \& Bradley, B. P. (1999). Orienting of attention to threatening facial expressions presented under conditions of restricted awareness. Cognition and Emotion, 13(6), 713-740. https://doi.org/10. 1080/026999399379050
Moran, T. P., \& Moser, J. S. (2015). The color of anxiety: Neurobehavioral evidence for distraction by perceptually salient stimuli in anxiety. Cognitive, Affective, \& Behavioral Neuroscience, 15(1), 169-179. https://doi.org/10.3758/s13415014-0314-7

Öhman, A. (2005). The role of the amygdala in human fear: Automatic detection of threat. Psychoneuroendocrinology, 30(10), 953-958. https://doi.org/10.1016/j.psyneuen.2005.03.019

Öhman, A., Flykt, A., \& Esteves, F. (2001). Emotion drives attention: Detecting the snake in the grass. Journal of Experimental Psychology: General, 130(3), 466-478. https://doi.org/10.1037/ 0096-3445.130.3.466

Öhman, A., \& Mineka, S. (2001). Fears, phobias, and preparedness: Toward an evolved module of fear and fear learning. Psychological Review, 108(3), 483-522. https://doi.org/10.1037// 0033-295X.108.3.483

Peirce, J. (2009). Generating stimuli for neuroscience using PsychoPy. Frontiers in Neuroinformatics, 2, 10. https://doi.org/10.3389/neuro. 11.010.2008

Pessoa, L. (2005). To what extent are emotional visual stimuli processed without attention and awareness? Current Opinion in Neurobiology, 15(2), 188-196. https://doi.org/10.1016/j.conb.2005.03.002

Qi, S., Ding, C., \& Li, H. (2014). Neural correlates of inefficient filtering of emotionally neutral distractors from working memory in trait anxiety. Cognitive, Affective, \& Behavioral Neuroscience, 14(1), 253-265. https://doi.org/10.3758/s13415-013-0203-5

Salahub, C., Lockhart, H. A., Dube, B., Al-Aidroos, N., \& Emrich, S. M. (2019). Electrophysiological correlates of the flexible allocation of visual working memory resources. Scientific Reports, 9:19428. https://doi.org/10.1101/746164

Sawaki, R., Geng, J. J., \& Luck, S. J. (2012). A common neural mechanism for preventing and terminating the allocation of attention. The Journal of Neuroscience, 32(31), 10725-10736. https://doi.org/10. 1523/JNEUROSCI.1864-12.2012

Sawaki, R., \& Luck, S. J. (2010). Capture versus suppression of attention by salient singletons: Electrophysiological evidence for an automatic attend-to-me signal. Attention, Perception, \& Psychophysics, 72(6), 1455-1470. https://doi.org/10.3758/APP.72.6.1455

Sawaki, R., \& Luck, S. J. (2013). Active suppression after involuntary capture of attention. Psychonomic Bulletin \& Review, 20(2), 296301. https://doi.org/10.3758/s13423-012-0353-4

Sessa, P., Luria, R., Gotler, A., Jolicœur, P., \& Dell'acqua, R. (2011). Interhemispheric ERP asymmetries over inferior parietal cortex reveal differential visual working memory maintenance for fearful versus neutral facial identities. Psychophysiology, 48(2), 187-197. https://doi.org/10.1111/j.1469-8986.2010.01046.x

Shackman, A. J., Stockbridge, M. D., Tillman, R. M., Kaplan, C. M., Tromp, D. P. M., Fox, A. S., \& Gamer, M. (2016). The neurobiology of dispositional negativity and attentional biases to threat: Implications for understanding anxiety disorders in adults and youth. Journal of Experimental Psychopathology, 7(3), 311-342. https://doi.org/10.5127/jep.054015

Spielberger, C. D., Gorsuch, R. L., Lushene, R., \& Vagg, P. R. (1983). Manual for the State-Trait Anxiety Inventory. Consulting Psychologists Press.

Stout, D. M., Shackman, A. J., \& Larson, C. L. (2013). Failure to filter: Anxious individuals show inefficient gating of threat from working memory. Frontiers in Human Neuroscience, 7, 58. https://doi.org/ 10.3389/fnhum.2013.00058

Stout, D. M., Shackman, A. J., Pedersen, W. S., Miskovich, T. A., \& Larson, C. L. (2017). Neural circuitry governing anxious individuals' mis-allocation of working memory to threat. Scientific Reports, 7(1), 8742. https://doi.org/10.1038/s41598-017-08443-7

JASP Team. (2020). JASP (0.12) [Computer software].

Vogel, E. K., McCollough, A. W., \& Machizawa, M. G. (2005). Neural measures reveal individual differences in controlling access to 
working memory. Nature, 438(7067), 500-503. https://doi.org/10. 1038/nature04171

Weaver, M. D., van Zoest, W., \& Hickey, C. (2017). A temporal dependency account of attentional inhibition in oculomotor control. NeuroImage, 147, 880-894. https://doi.org/10.1016/j.neuroimage. 2016.11.004

Weymar, M., Löw, A., Öhman, A., \& Hamm, A. O. (2011). The face is more than its parts - Brain dynamics of enhanced spatial attention to schematic threat. NeuroImage, 58(3), 946-954. https://doi.org/10. 1016/j.neuroimage.2011.06.061
Woodman, G. F., \& Luck, S. J. (2003). Serial deployment of attention during visual search. Journal of Experimental Psychology: Human Perception and Performance, 29(1), 121-138. https://doi.org/10. 1037/0096-1523.29.1.121

Publisher's note Springer Nature remains neutral with regard to jurisdictional claims in published maps and institutional affiliations. 